\title{
Do we need guidelines or 'songlines'?
}

\section{Norman L Jones MD, Editor-in-Chief, Canadian Respiratory Journal}

$\mathrm{W}$ ith the current issue of the Canadian Respiratory Journal we are delighted to publish a supplement featuring an update to the Canadian Asthma Consensus Guidelines. Since the publication of the first evidence-based guidelines in 1996 (1), an update was published in 1999 (2); the present update is the result of hard work by Dr LouisPhilippe Boulet's committee over the past year. We may reflect not only on the extent of changes to the guidelines and the speed with which they were made, but also on the extent to which they are used and their influence on current asthma management.

By reading the admirably concise contributions to the present update, we gain an impression of the increasing research into the development of new approaches to asthma treatment on the part of the pharmaceutical industry, and the increasing quality and breadth of research on the part of the academic community in Canada. New drugs are being tested rigorously, and the clinical studies are increasingly accompanied by quality-of-life and economic impact studies. Older approaches are being questioned and replaced in the light of new information; one needs only to remember the conventional management of mild asthma of a few years ago - with its emphasis on regular use of bronchodilators by mouth and inhalation to the more modern use of inhaled steroids and 'as needed' beta-agonists - to realize how much and how rapidly things have changed.

Notable in the update is new information on the importance of educational interventions and environmental control; clinical clues and objective measurements in young children; the use of quantitative cytology on induced sputum samples; newer inhaled steroid preparations; and the present status of leukotriene receptor antagonists. The reference lists provide a useful summary of the up-to-date literature on each topic.

Despite the dissemination of guidelines and the recent research, Dr Boulet - in his introduction to the updated asthma guidelines (3) - sounds a cautionary note when he identifies gaps (Table 3 of his paper) in the implementation of proven management strategies. He identifies insufficient patient education, poor use of objective measures of asthma severity, misunderstandings in the roles of different drugs, overuse of beta2-agonists and underuse of anti-inflammatory agents, and a discontinuity of patient care. All of these gaps have been highlighted in past guideline publications.

The pace of change and rapidity with which guidelines are updated may seem to militate against their use

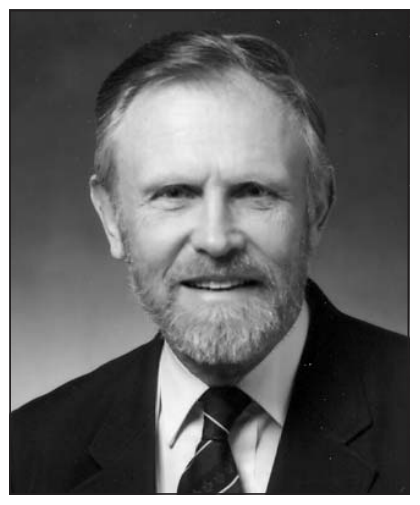
in practice, but all specialties face this problem. For example, guidelines for the management of hypertension are updated on a yearly basis. If the changes in guidelines are rigorously evidence based, yearly updates are readily justified. However, the rapidity of change can hardly explain the continuation of deficiencies that were recognized as long as five years ago.

The difficulty of implementing guidelines into practice is emphasized by three other papers in the supplement and in the current issue of the Journal. Dr Putnam and his colleagues (4) involved 20 family physicians in discussions about asthma guidelines, and found a tendency to rely on clinical judgment in preference to airflow measurements and a reluctance to use anti-inflammatory agents. Dr Chapman and co-workers (5) undertook a telephone survey study of patients with asthma: only $50 \%$ could remember having spirometry and over $50 \%$ failed to meet the criteria for symptom control. They concluded that a majority of asthma patients suffer inadequate control (5). Dr Cowie and his group (6) compared three communities in which different levels of asthma education were provided, and they were unable to show any beneficial effects of intensive patient education; however, in addition, the 1996 guidelines were widely distributed to physicians in all three communities.

Perhaps similar or linked factors underlie the reliance on clinical judgment and the underuse of objective measurements. There is ample evidence that clinical assessment based on symptoms and signs can be extremely misleading, but perhaps this does not hit home until we have a lot of experience 
in the use of the measurements, providing us individually with evidence that we need measurements to assess asthma severity objectively. Ever since I was asked to write an article 30 years ago for the Canadian Family Physician (7) to review the assessment of airway obstruction, I have been puzzled by the fact that no family practice seems to use a spirometer. The methods are so simple that there is no reason for this; perhaps spirometry has been made to appear too complicated. A colleague of mine who reviewed a paper describing the assessment of patients in the emergency room, and who questioned why spirometry had not been carried out, received the response that this was because the standards set out by the American Thoracic Society could not be guaranteed. Perhaps these rigorous standards militate against the common sense use of spirometry in practice - another example of political correctness acting against the common good. Even peak flow rates are seldom used, except in specialty clinics; Dr Putnam's study (4) identified poor patient compliance as "limiting the usefulness" of this method, a reason that is clearly absurd to anyone who has used it frequently.

Leaving the issue of objective measurement aside, we have to question why guidelines are not incorporated into practice. Perhaps none of us much likes being told what to do, or perhaps the guidelines are just not 'user friendly'.

Which brings me to The Songlines. I realize that I am stretching things a little, but bear with me in the spirit of literary licence. The Songlines is the title of a fascinating book by the late Bruce Chatwin (8) about his research into the labyrinth of invisible pathways that meander across the interior of Australia. The pathways consist of the "Footprints of the Ancestors": these legendary beings wandered through the seemingly featureless landscape, singing out the names of rocks, trees, hills and watercourses; their descendants found their way by singing the songs, turning Australia into a virtual musical score. In the Guidelines, we have material for songs that point the way or remind us of the best way to manage asthma, but none of us can recite it without a lot of thought.
Nowadays, all of us have ready access to computers that could allow us to compose songlines that would be applicable to an individual patient who presents with possible asthma, taking us through the key clinical questions and investigations (where indicated), and pointing the way to individualized action plans. Such clinical decision support systems (CDSSs) are able to improve clinical decisions and patient outcomes (9), and they also provide an excellent problem-based learning tool. Hunt et al (10) reviewed 68 randomized, controlled trials of CDSSs, concluding that they significantly improved clinical performance and patient outcome, especially through better active and preventive care. Although four of the reviewed studies were targeted at aminophylline dosing, there does not appear to have been a CDSS aimed at broad aspects of asthma management. Table 1 in Dr Boulet's introduction to the updated asthma guidelines (3) provides a logical structure on which to build such a system.

\section{REFERENCES}

1. Ernst P, FitzGerald JM, Spier S. Canadian Asthma Consensus Conference: Summary of recommendations. Can Respir J 1996;3:89-100.

2. Boulet L-P, Becker A, Bérubé D, Beveridge R, Ernst P, for the Canadian Asthma Consensus Group. Canadian Asthma Consensus Report, 1999. CMAJ 1999;161(11 Suppl):S1-61.

3. Boulet L-P, Bai TR, Becker A, et al. What is new since the last (1999) Canadian Asthma Consensus Guidelines? Can Respir J 2001;8(Suppl A):5A-27A.

4. Putnam W, Burge F, Tatemichi S, Twohig P. Asthma in primary care: Making guidelines work. Can Respir J 2001;8(Suppl A):29-34A.

5. Chapman KR, Ernst P, Grenville A, Dewland P, Zimmerman S. Control of asthma in Canada: Failure to achieve guideline targets. Can Respir J 2001;8(Suppl A):35A-40A.

6. Cowie RL, Underwood MF, Mack S. The impact of asthma management guideline dissemination on the control of asthma in the community. Can Respir J 2001;8(Suppl A):41A-5A.

7. Jones NL. Assessment of patients with chronic airway obstruction. Can Fam Phys 1970.

8. Chatwin B. The Songlines. Harmondsworth: Penguin Books, 1988.

9. Wyatt JC. Decision support systems. J R Soc Med 2000;93:629-33.

10. Hunt DL, Haynes RB, Hanna SE, Smith K. Effects of computer-based clinical decision support systems on physician performance and patient outcomes: a systematic review. JAMA 1998;280:1339-46. 


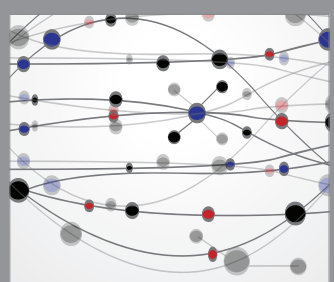

The Scientific World Journal
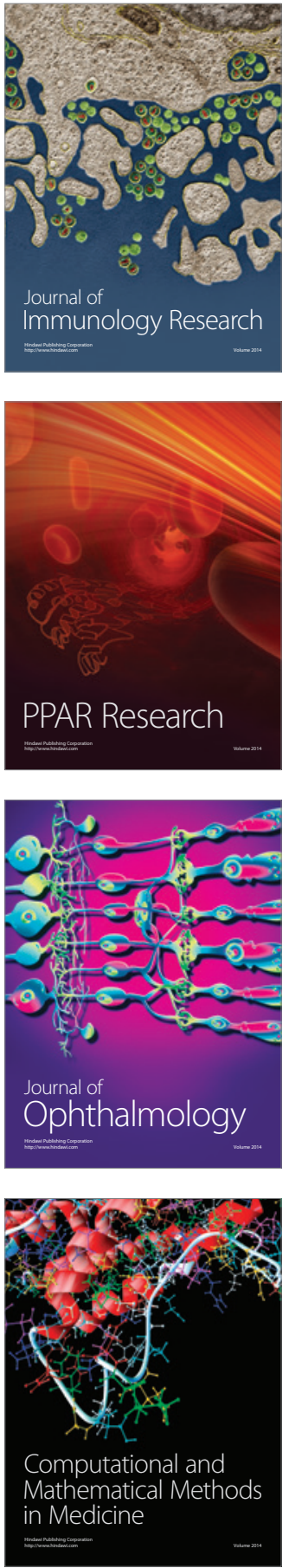

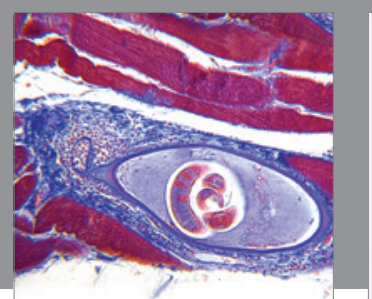

Gastroenterology Research and Practice

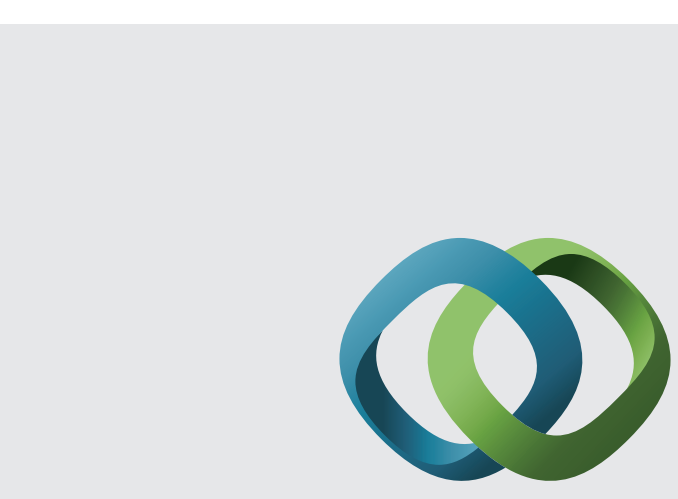

\section{Hindawi}

Submit your manuscripts at

http://www.hindawi.com
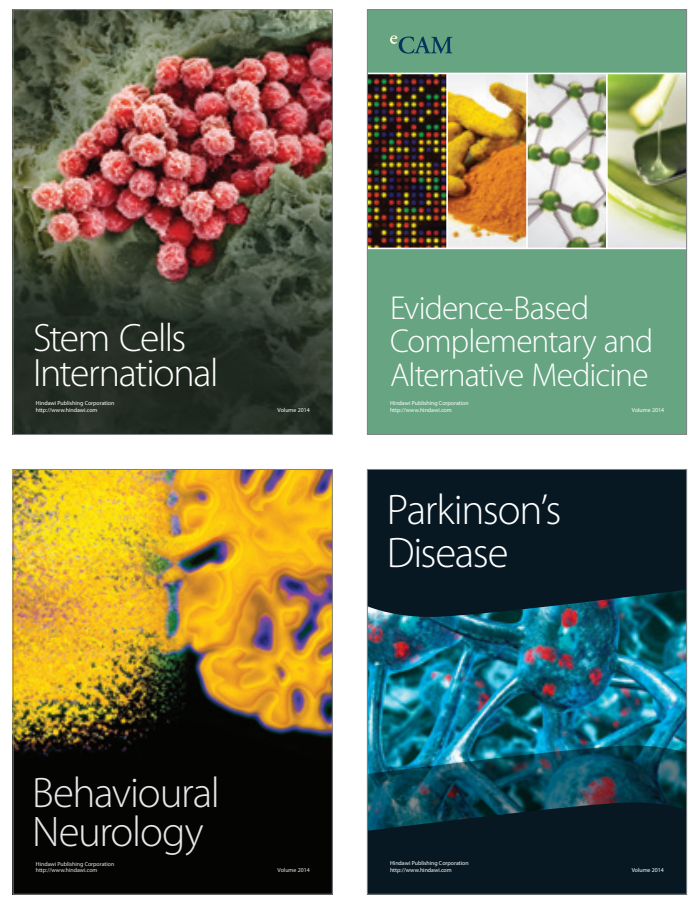
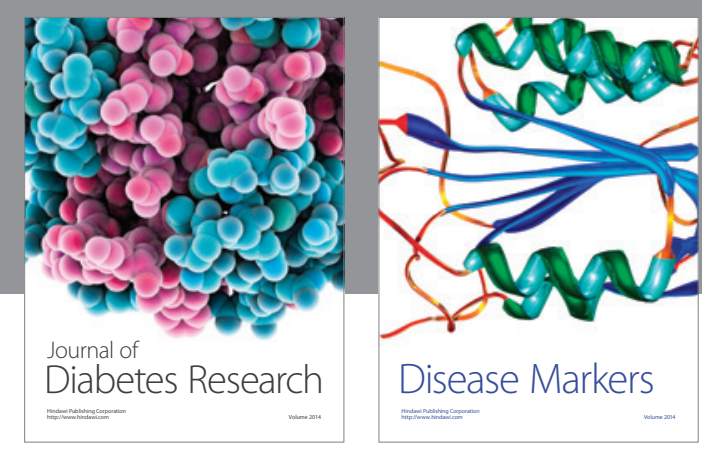

Disease Markers
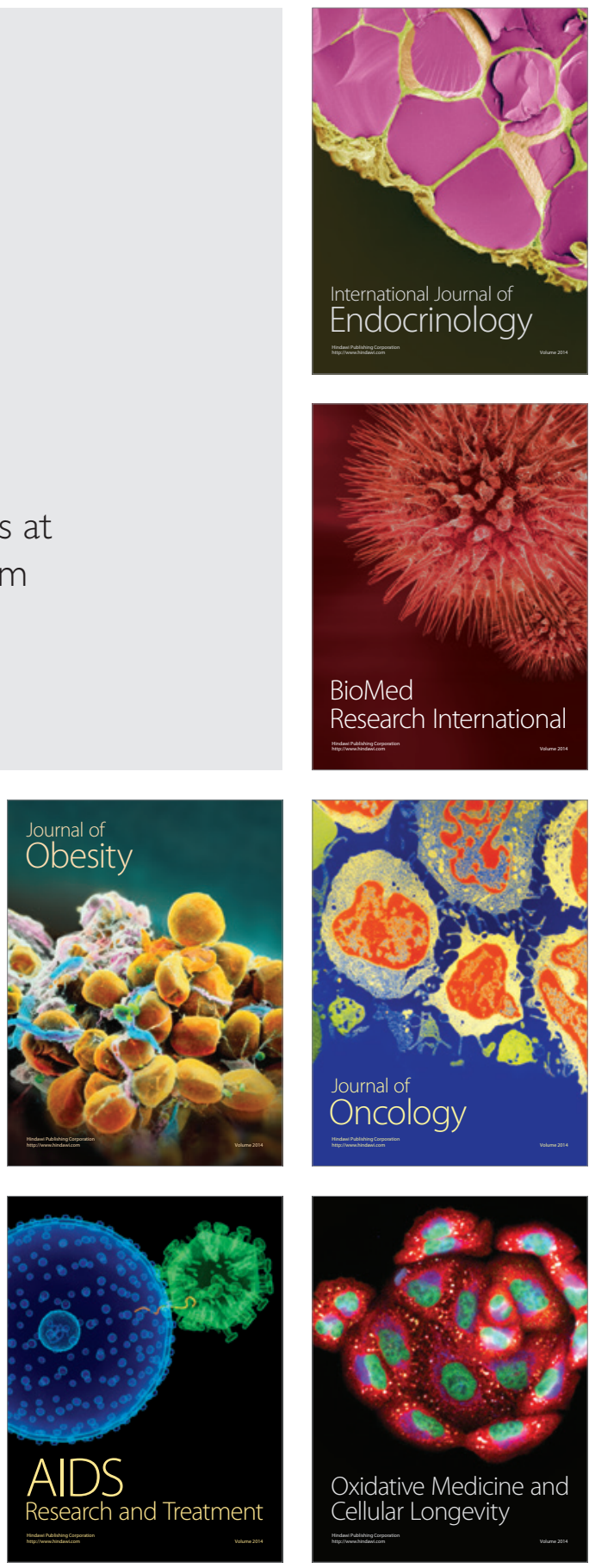